\title{
Uveítes anteriores associadas a doenças sistêmicas
}

\author{
Anterior uveitis associated tosystemic diseases
}

\author{
Maria Angélica Pavão Dimantas ${ }^{1}$ \\ Careen Lowder ${ }^{2}$ \\ Cristina Muccioli ${ }^{3}$
}

${ }^{1}$ Estagiária do Setor de Uveítes e AIDS do Departamento de Oftalmologia da Universidade Federal de São Paulo - UNIFESP;

2 Chefe do Setor de Uveítes da "Cleveland Clinic Foundation";

${ }^{3}$ Professora Afiliada e Chefe do Setor de Uveítes e AIDS do Departamento de oftalmologia da Universidade Federal de São Paulo- UNIFESP.

Endereço para correspondência: Rua Botucatu, 822 São Paulo (SP) CEP 04023-062

E-mail:madimantas@uol.com.br

Recebido para publicação em 16.01.2002

Aceito para publicação em 16.01.2003

\begin{tabular}{|l|}
\hline RESUMO \\
\hline As uveítes anteriores são caracterizadas pela inflamação preponderante \\
do segmento anterior do olho. Hiperemia conjuntival, reação de câmara \\
anterior com células e "flare", precipitados ceráticos e sinéquias posterio- \\
res são sinais que compõem o quadro inflamatório. Aspectos clínicos de \\
algumas doenças sistêmicas envolvidas na etiologia das uveítes anterio- \\
res serão abordados neste artigo.
\end{tabular}

Descritores: Uveíte/classificação; Uveíte anterior/etiologia; Uveíte anterior/diagnóstico; Doenças reumáticas; Artrite reumatóide juvenil/diagnostico; Toxoplasmose ocular/complications; Antígeno HLA-B27/análise

\section{INTRODUÇÃO E CLASSIFICAÇÃO}

Uveíte é o termo utilizado para definir a inflamação da íris, coróide e corpo ciliar. O nervo óptico e a retina podem também ser afetados. É uma importante causa de morbidade ocular e cegueira em vários países.

A elaboração de uma classificação internacional pelo International Uveitis Study Group (IUSG) (1987) ${ }^{(1)}$, teve um papel importante na padronização da nomenclatura e na compreensão dos fatores relacionadas à história natural dos diferentes tipos de uveítes.

Com base na localização anatômica da inflamação, as uveítes podem ser classificadas em quatro grupos: uveíte anterior (inflamação localizada na íris, ou corpo ciliar, ou ambos); uveíte intermediária (inflamação primária do corpo ciliar, coróide e retina periférica); uveíte posterior (inflamação primária da coróide) e uveíte difusa ou pan-uveíte (inflamação de todos os componentes anatômicos da úvea-íris, corpo ciliar e coróide).

As uveítes anteriores incluem termos previamente conhecidos como: irite (inflamação relacionada à íris, com células inflamatórias na câmara anterior e sem acometimento do vítreo anterior), iridociclite (inflamação primária da íris, com inflamação secundária do corpo ciliar, as células inflamatórias estarão presentes tanto na câmara anterior quanto no vítreo anterior) e ciclite (inflamação presente principalmente no corpo ciliar).

Outra classificação das uveítes é relacionada a um termo utilizado pela anatomopatologia, que pode ser utilizado para auxiliar tanto no diagnóstico quanto na classificação das uveítes: granulomatosa e não granulomatosa. Uveíte granulomatosa é caracterizada pela tendência a formação de nódulos de íris (Koeppe ou Bussaca) e precipitados ceráticos "mutton fat". Uveíte não granulomatosa tem pequena ou nenhuma tendência à formação tanto de nódulos quanto de precipitados $\operatorname{ceráticos}^{(2)}$.

As uveítes cuja inflamação duram semanas ou poucos meses, e que terminada a crise desaparecem, são chamadas uveítes agudas.

Nas uveítes crônicas a inflamação dura meses ou anos, sem seu desaparecimento completo entre os períodos de exacerbação.

As classificações acima têm sido úteis no desenvolvimento de novos exames laboratoriais e testes oftalmológicos auxiliares. 
O diagnóstico da uveíte anterior é baseado na anamnese completa do paciente, exame ocular minucioso bilateral e avaliação sistêmica e laboratorial pertinente.

A anamnese e o exame físico fornecem informações sobre doenças sistêmicas, tais como artrite, doenças gastrintestinais, infecções venéreas e doenças dermatológicas e do sistema nervoso central. Dados pessoais importantes com relação a sexo, idade, procedência, podem também ser obtidos através da anamnese. Algumas doenças ocorrem na infância e outras em faixas etárias mais avançadas.

A avaliação clínica do oftalmologista é de suma importância no estabelecimento do diagnóstico do paciente com uveíte. Os exames laboratoriais devem ser pedidos apenas depois de achados clínicos e exame ocular e físico direcionados para determinados diagnósticos diferenciais entre os muitos possíveis.

\section{UVEÍTES ANTERIORES INFECCIOSAS}

\section{Tuberculose}

A tuberculose pode afetar os olhos de muitas maneiras: granuloma de conjuntiva, ceratite intersticial, doença flictenular, episclerite, uveíte anterior (granulomatosa ou não), vasculite retiniana e corresponde a cerca de 1 a $3 \%$ dos casos de uveíte, acompanhando o aumento do número de casos de tuberculose sistêmica após a pandemia da $\operatorname{AIDS}^{(3)}$.

Os achados oculares mais freqüentes da uveíte anterior relacionados à tuberculose são: precipitados ceráticos granulomatosos e nódulos de íris. A iridociclite, na ausência de tratamento específico, progride lentamente até o envolvimento do vítreo, retina, coróide e nervo óptico ${ }^{(4)}$. Os oftalmologistas devem estar atentos a uveíte anterior não responsiva à medicação tópica, para a investigação de tuberculose.

Sinais sistêmicos tais como perda de peso, febre, suores noturnos e sintomas respiratórios podem sugerir infecção sistêmica ativa. $\mathrm{O}$ envolvimento ocular (uveíte anterior ou coroidite focal) pode ocorrer na ausência de tuberculose sistêmica ativa.

\begin{tabular}{|l|}
\hline \multicolumn{2}{|c|}{ Avaliação básica nas uveítes anteriores } \\
Iridociclite em crianças (abaixo de 15 anos) \\
- Anticorpo antinuclear (ANA) \\
- FTA-ABS/ VDRL \\
- Raio X tórax \\
- Avaliação para sarcoidose \\
- PPD \\
- Raio X joelhos (ARJ) \\
Iridociclite em adultos \\
- Raio X tórax \\
- PPD \\
- FTA-ABS/VDRL \\
- Raio X juntas sacroilíacas nos homens (EA) \\
- HLA B27 nos homens (EA) \\
\hline
\end{tabular}

\begin{tabular}{|ll|}
\hline \multicolumn{2}{|c|}{ Testes laboratoriais nas uveítes anteriores } \\
Uveíte & \multicolumn{1}{c|}{ Exames Laboratoriais } \\
- HLA B27 & $\begin{array}{l}\text { - VHS, HLA B27, raio X juntas sacroilía- } \\
\text { cas, pesquisa para Clamídia, fixação } \\
\text { - de complemento }\end{array}$ \\
- ARJ & - VHS, ANA \\
- Tuberculose & - PPD, raio X tórax \\
- Sarcoidose & Raio X tórax, TC tórax, biópsia \\
- conjulis & - Sorologial, Gálio scan, ECA \\
\hline
\end{tabular}

A tuberculose é uma das causas de uveíte nas quais os testes cutâneos podem ser úteis ${ }^{(5)}$. O teste de PPD (purified protein derivated), que é padronizado internacionalmente, é utilizado para auxiliar no diagnóstico da tuberculose, sendo classificado em três categorias de acordo com sua enduração: não reatores, reatores fracos e reatores fortes. A positividade do PPD não está diretamente relacionada à doença tuberculose e sim à infecção, sendo necessárias evidências de doença ativa.

A vacinação com o BCG também desencadeia reação tuberculínica, que tende a ser menor em enduração e menos duradoura, tornando-se geralmente negativa após cinco anos de vacinação.

O raio-X de tórax é de fácil realização e de custo baixo como passo inicial na investigação da tuberculose. Quando o resultado do exame é duvidoso, pode ser solicitada uma tomografia computadorizada para melhor avaliação.

\section{Sífilis}

A sífilis ocular manifesta-se através de várias apresentações clínicas, sendo responsável por 2 a $8 \%$ de todas as uveítes $^{(6)}$. A uveíte anterior relacionada à infecção por sífilis pode ser grave e não responsiva à medicação. Os achados oculares mais freqüentes são a iridociclite com precipitados ceráticos granulomatosos e dilatação das alças vasculares da íris que leva a formação discreta das "roséolas" irianas.

Os achados oculares incluem uveíte posterior com envolvimento retiniano, papilite com dilatação venosa e hemorragias em chama de vela peripapilares. Retinite necrosante e vasculite retiniana também podem ser encontrados.

Os testes para pesquisa da sífilis incluem FTA-ABS (fluorescent treponemal antibody absorption test) e VDRL (venereal disease reserch laboratory test).

O FTA-ABS é considerado um dos mais específicos e de alta sensibilidade para o diagnóstico da sífilis. É fracamente reativo ou não reativo, e uma vez que o paciente tenha tido sífilis mantém-se positivo por toda a vida ${ }^{(7)}$.

O VDRL é um dos testes mais utilizados no diagnóstico da sífilis. Embora propenso a falsos positivos e resultados negativos, é quantitativo e se converte em títulos baixos, podendo ser negativo após tratamento adequado.

Dois testes específicos novos para sífilis são o de microaglutinação de anticorpos do T. pallidum (MHA-TP) e de he- 
maglutinação treponêmica (TPHA). Estes dois testes são comparáveis ao FTA-ABS em sensibilidade e especificidade.

As indicações para o exame do liquido cefalorraquidiano (LCR) são relacionadas à presença de inflamação intra-ocular, alterações pupilares com sinais de disfunção neuroftálmica, infecção pelo HIV e falência do tratamento.

No exame do LCR devem ser avaliados: pressão, aspecto, bioquímica, bacterioscopia e sorologia. É importante observar que alterações do sistema nervoso central (SNC) podem ser encontradas nas infecções agudas ou crônicas, doenças degenerativas, neuropatias, tumores e doenças cerebrovasculares. Pleocitose com linfócitos podem ser encontrados em meningites virais, neurotuberculose e neurossífilis.

\section{UVEÍTES ANTERIORES NÃO INFECCIOSAS}

\section{Sarcoidose}

A sarcoidose é uma doença granulomatosa multisistêmica de etiologia desconhecida, que pode afetar os olhos. As manifestações oculares incluem nódulos palpebrais e conjuntivais, uveíte anterior granulomatosa, uveíte posterior, retinite, neuropatia óptica e dacrioadenite. É responsável por 10 a 20\% de todas as uveítes ${ }^{(8)}$.

A manifestação ocular mais comum é a iridociclite caracterizada por precipitados ceráticos "mutton fat" muito grandes, sinéquias posteriores, "flare" e células em grande quantidade na câmara anterior, podendo ser crônica, recorrente e parcialmente responsiva a corticoterapia tópica e sistêmica.

Embora a hipercalcemia ocorra em cerca de $25 \%$ dos pacientes com sarcoidose sistêmica, o aumento do cálcio sérico é raramente observado nos casos oculares, nos quais ocorre remissão sistêmica.

A enzima conversora da angiotensina (ECA) é produzida por várias células do corpo, entre elas, as células do endotélio capilar e monócitos, que são convertidos em células secretoras. Os valores normais dependem da técnica utilizada e os níveis séricos da ECA estão elevados na maioria dos casos de sarcoidose sistêmica ativa e outras situações que incluem hanseníase, tuberculose, histoplasmose, carcinomatose, linfomatose, granulomatose e sarcoma imunoblástico ${ }^{(9)}$. Na infância podemos também encontrar níveis séricos da ECA aumentados.

Freqüentemente, pacientes com sarcoidose ocular ativa estão em remissão sistêmica e a ECA cai aos níveis normais, não havendo elevação com a atividade ocular isolada. Entretanto, os níveis normais da ECA não descartam o diagnóstico de uveíte por sarcoidose.

A despeito de todas as limitações e da ausência de testes melhores, a dosagem sérica da ECA, combinada ao mapeamento com gálio, ainda são considerados métodos sensíveis no diagnóstico da sarcoidose ${ }^{(10)}$.

Embora não específico, o mapeamento com gálio é uma ferramenta valiosa na avaliação diagnóstica da sarcoidose. $\mathrm{O}$ citrato radioativo de gálio 67 localiza áreas de atividade inflamatória nas quais macrófagos e células epitelióides são participantes proeminentes. É um exame sensível para detecção do envolvimento em áreas como nódulos linfáticos mediastinais, parênquima pulmonar, glândula submandibular e parótidas. $\mathrm{O}$ acúmulo anormal de gálio é radiograficamente detectável em pacientes com sarcoidose ${ }^{(11)}$. O diagnóstico definitivo é confirmado com a biópsia tecidual demonstrando granuloma não caseoso de células epitelióides.

\section{Doença de Behçet}

Trata-se de uma vasculite sistêmica generalizada e crônica, classificada como autoimune, que apresenta características clínicas variadas. Tem preferência pelos vasos de pequeno calibre (principalmente venosos), podendo causar alterações em praticamente todos os órgãos. Seus sinais mais freqüentes são as úlceras orais e genitais, ocorrendo também manifestações oculares, dérmicas, neurais, pulmonares e outras.

A etiologia da doença de Behçet permanece desconhecida, sendo que diversos fatores mostraram-se envolvidos com o seu aparecimento, tais como: vírus (Herpes simplex, adenovírus), exposição a antígenos estreptocócicos, hereditariedade (HLA B51).

O acometimento ocular é freqüente na doença de Behçet, podendo variar entre a iridociclite aguda não granulomatosa, com hipópio (um terço dos casos) ou vasculite retiniana ${ }^{(12)}$.

Não há um teste diagnóstico específico para a doença de Behçet. O quadro clínico é composto por sinais considerados maiores e menores na formulação dos critérios utilizados na hipótese diagnóstica da doença de Behçet.

São utilizados como dados inespecíficos a reação de hipersensibilidade cutânea (patergia), aumento da atividade quimiotática dos neutrófilos e da imunidade celular, elevados níveis séricos de $\mathrm{C} 9$ e outros ${ }^{(13)}$.

\section{Artrite Reumatóide (AR)}

A AR é uma doença crônica e progressiva caracterizada pela sinovite poliarticular, que afeta aproximadamente $1 \%$ de todas as pessoas ao redor do mundo. O comprometimento ocular inclui ceratoconjuntivite seca, esclerite anterior, episclerite, ceratopatia e uveíte anterior ${ }^{(14)}$.

O fator reumatóide (FR) nas uveítes pode ser útil em algumas condições. A maioria dos pacientes com AR, lúpus eritematoso sistêmico, síndrome de Sjögren, hepatite ativa crônica, doenças do tecido conectivo e infecções crônicas tem FR positivo. Pacientes com ARJ, artrite psoriática, artrite associada à colite ulcerativa, enterite, síndrome de Reiter e espondilite ancilosante têm FR negativo.

\section{Artrite Reumatóide Juvenil (ARJ)}

A ARJ é a doença reumática mais comum na infância, podendo afetar pessoas abaixo dos 16 anos, com início geralmente entre dois e quatro anos. A iridociclite é o achado ocular mais freqüente e quando não diagnosticada ou mantida sem tratamento, pode levar a cegueira nesses pacientes. 
A inflamação intra-ocular na ARJ é caracterizada por uveíte anterior não granulomatosa. A inflamação é crônica e leve e o paciente nunca apresenta o "olho vermelho". Algumas vezes a uveíte é notada quando algumas de suas complicações instalam-se (perda visual, catarata, ceratopatia em faixa) ${ }^{(15)}$.

Diferentemente da AR, o FR é raramente positivo nos pacientes com ARJ.

O teste de fluorescência, com anticorpos antinucleares (ANA), não é específico para todos os anticorpos antinucleares encontrados no soro. Os níveis de ANA séricos podem estar elevados em muitas doenças tais como, ARJ, Lupus Eritematoso Sistêmico (LES) periarterite nodosa, dermatomiosite, esclerodermia, hepatite crônica, pneumonia atípica, carcinoma, linfoma, doença de Raynaud e síndrome de Sjögren. Este teste é importante no diagnóstico de uveíte porque se mantém positivo permanentemente em $80 \%$ dos pacientes com iridociclite associada a ARJ. Deve ser enfatizado que de acordo com alguns autores, um único teste negativo não é conclusivo; deve ser negativo em três ou quatro amostras para ser conclusivo $^{(16)}$.

\section{Espondiloartropatias soronegativas}

As espondiloartropatias soronegativas representam $52 \%$ de todos os casos de uveíte anterior e incluem as uveítes anteriores relacionadas ao (HLA - Human leucocyte Antigen) HLA B27, síndrome de Reiter, doença intestinal inflamatória, espondilite ancilosante e artrite psoriática ${ }^{(17)}$.

As uveítes relacionadas ao HLA B27 são caracterizadas como unilaterais, fulminantes, com fibrina e células na câmara anterior.

A conjuntivite é o achado ocular mais comum nos pacientes com síndrome de Reiter, afetando aproximadamente 30 a $60 \%$ de todos os pacientes, sendo geralmente bilateral e autolimitada ${ }^{(18)}$. Iridociclite recorrente grave com borramento visual, sinéquias posteriores, precipitados ceráticos, células e fibrina na câmara anterior podem estar presentes e o paciente pode queixar-se de fotofobia e olho vermelho.

A iridociclite é aguda com início súbito nos pacientes com espondilite ancilosante. As queixas dos pacientes incluem fotofobia importante, olho vermelho e borramento visual relacionados à reação de câmara anterior moderada a grave. Pequenos precipitados ceráticos, sinéquias posteriores, hipópio inflamatório e glaucoma secundário podem ser encontrados. A iridociclite não granulomatosa, leve ou grave, pode ser recorrente e afetar um olho de cada vez. Raios-X de articulações sacroilíacas em pacientes masculinos com iridociclite recorrente pode ajudar no diagnóstico de espondilite ancilosante.

Antígenos de histocompatibilidade humana (HLA human leucocyte antigen) estão presentes na superfície da maioria das células nucleadas. Devido à facilidade de acesso, os leucócitos são as células mais utilizadas no estudo do HLA. Foi determinado que algumas doenças humanas são associadas com a presença ou ausência de certos antígenos HLA. Cinco séries de HLA foram identificadas. Os “loci” A, B,
C, D, ou DR (relacionado ao D) foram localizados no cromossomo 6. Nas uveítes, o exemplo clássico de associação é com o HLA B27 que desde sua descoberta é encontrado em 80-90\% dos pacientes com síndrome de Reiter e espondilite ancilosante $(5-8 \% \text { na população normal })^{(19)}$. Também está presente em $40 \%$ dos pacientes com ARJ.

\section{ABSTRACT}

Anterior uveitis describes a disease predominantly limited to the anterior segment of the eye. Conjunctival hyperemia, anterior chamber cell and flare, keratic precipitates, and iris abnormalities including posterior synechiae characterize the inflammation. This article discusses clinical aspects of the systemic diseases that cause anterior uveitis with review of the literature.

Keywords: Uveitis/classification; Anterior uveitis/etiology; Anterior uveitis/diagnosis; Rheumatic diseases; Juvenile rheumatoid arthritis/diagnosis; Ocular toxoplasmosis/complications; HLA-B27 antigen/analysis

\section{REFERÊNCIAS}

1. Bloch-Michel E, Nussenblatt RB. International Uveitis Group recommendations for the evaluation of intraocular inflammatory disease. Am J Ophthalmol 1987; 103:234-5.

2. Oréfice F, Belfort JR. Uveítes. São Paulo; 1987.

3. Small PM, Schecter GF, Goodman PC, Sande MA, Chaisson RE, Hopewell PC. Treatment of tuberculosis in patients with advanced human immunodeficiency virus infection. N Engl J Med 1991;324:289-94.

4. Helm CJ, Holland GN. Ocular tuberculosis. Surv Ophthalmol 1993;38:229-56.

5. Abrams J, Schlaegel Jr TF. The tuberculin skin test in the diagnosis of tuberculosis uveitis. Am J Ophthalmol 1983;96:295-8.

6. Schlaegel TF Jr, Kao SF. A review (1970-1980) of 28 presumptive cases of syphilitic uveitis. Am J Ophthalmol 1982;93:412-4.

7. Veronesi R, Foccacia R. Tratado de infectologia. São Paulo: Atheneu; 1997.

8. Rothova A, Buitenhuis HJ, Meeken C, Brinkman CJ, Linssen A, Alberts C, et al. Uveitis and systemic disease. Br J Ophthalmol 1992;76:137-41.

9. Baarsma GS, La Hey E, Glasius E, de Vries J, Kijlstra A The predictive value of serum angiotensin converting enzyme and lysozyme levels in the diagnosis of ocular sarcoidosis. Am J Ophthalmol 1987;104:211-7.

10. Power WJ, Neves RA, Rodriguez A, Pedroza-Seres M, Foster CS. The value of combined serum angiotensin-converting enzyme and gallium scan in diagnosing ocular sarcoidosis. Ophthalmology 1995;102:2007-11.

11. Karma A, Poukkula AA, Ruokoen AO. Assessment of activity of ocular sarcoidosis by gallium scanning. Br J Ophthalmol 1987;71:361-7.

12. Barra C, Belfort Jr R, Abreu MT, Kim MK, Martins MC, Petrilli AMN. Behçet 's disease in Brazil: a review of 49 cases with emphasis on ophthalmic manifestations. Jpn J Ophthalmol 1991;35:399-46.

13. Abreu MT, Bonfioli AA, Oréfice F. Doença de Behçet. In Oréfice F. Uveítes: clínica e cirúrgica. Rio de Janeiro: Cultura Médica; 2000.

14. Wakefield D, Montanaro A, McCluskey P. Acute anterior uveitis and HLAB27. Surv Ophthalmol 1991;36:223-32.

15. Wolf MD, Lichter PR, Ragsdale CG. Prognostic factors in the uveitis of juvenile rheumatoid arthritis. Ophthalmology 1987;94:1242-8.

16. Pepose JS, Holland GN, Wilhelmus KR. Ocular infection and immunity. St. Louis: Mosby; 1996.

17. Nussenblatt RB, Whitcup SM, Palestine AG, Uveitis: fundamentals and clinical practice. St. Louis: Mosby; 1986.

18. Lee DA, Barker SM, Su WP, Allen GL, Liesegang TJ, Ilstrup DM. The clinical diagnosis of Reiter's syndrome. Ophthalmology 1986;93:350-6.

19. Tay-Kearney M, Schwan BL, Lowder CY, Dunn JP, Meisler DM, Vitale S, et al. Clinical features and associated systemic diseases of HLA-B27 uveitis. Am J Ophthalmol 1996;121:47-56. 